\title{
Controlled Crack Growth Specimen for Brittle Systems
}

\author{
Anthony M. Calomino
}

Lewis Research Center

Cleveland, Ohio

and

David N. Brewer

Propulsion Directorate

U.S. Army Aviation Research and Technology Activity-AVSCOM

Lewis Research Center

Cleveland, Ohio

May 1990 


\title{
CONTROLLED CRACK GROWTH SPECIMEN FOR BRITTLE SYSTEMS
}

\author{
Anthony M. Calomino \\ National Aeronautics and Space Administration \\ Lewis Research Center \\ Cleveland, Ohio 44135 \\ and \\ David N. Brewer \\ Propulsion Directorate \\ U.S. Army Aviation Research and Technology Activity - AVSCOM \\ Lewis Research Center \\ Cleveland, Ohio 44135
}

\section{SUMMARY}

A pure Mode I fracture specimen and test procedure has been developed which provides extended, stable, through-thickness crack growth in ceramics and other brittle, nonmetallic materials. Fixed displacement loading, applied at the crack mouth, promotes stable crack extension by reducing the stored elastic strain energy. Extremely fine control of applied displacements is achieved by utilizing the Poisson's expansion of a compressively loaded cylindrical pin. Stable cracks have been successfully grown in soda-lime glass and monolithic $\mathrm{Al}_{2} \mathrm{O}_{3}$ for lengths in excess of $20 \mathrm{~mm}$ without uncontrollable catastrophic failure.

\section{INTRODUCT ION}

The ability to measure fatigue crack growth and fracture properties for brittle naterials and material systems has been hindered by the inability to induce and observe controlled crack growth. Sustaining stable crack growth in most brittle materials is complicated by a low damage tolerance and relative high material stiffness. Elastic energy, stored in the loading fixture, is transferred to the specimen during crack extension. This unavoidable transfer of stored elastic energy is sufficient to cause unstable crack propagation.

A specimen design and loading technique has been developed which enables controlled Mode I crack growth studies to be performed in monolithic ceramics and other brittle materials. The loading system approaches a "true" fixed displacement test by maintaining high loading stiffness and proposes a solution to gripping and grip alignment problems inherent in brittle testing. The unique method used to load the specimen minimizes the influence that specimen stiffness has on the effective stiffness of the load train. The testing procedure appears to be readily adaptable to a variety of test conditions such as elevated temperature tests, fatigue crack growth tests, and dynamic loading tests. Tests have thus far been conducted under monotonically increasing displacements, however fatigue crack growth studies are planned.

\section{STABLE CRACK GROWTH SPECIMENS}

The initiation and control of a sharp Mode I crack in ceramics has been an experimental challenge due to low damage tolerance and relatively high bulk 
modulus. Traditionally it has been thought that load frames must be very stiff and possess a high degree of control on the loading rate to be used for ceramic fracture testing. The problems associated with ceramic testing have led to innovative specimen designs and loading fixtures. However, currently available techniques are not well suited for quantitative studies of stable crack growth under true Mode I loading. This is particularly true if one wishes to study stable crack growth in specimens with a uniform cross section.

Chevron notched (CN) specimens (refs, 1 and 2) are some of the first test geometries used to produce stable crack growth in brittle materials. Propagation stability is imposed through a geometrically increasing crack front width which effectively increases the fracture resistance of the specimen. Chevron notched specimens were originally employed to evaluate the work of fracture in glasses and ceramics (refs. 3 and 4 ) and have proved to be very useful for a variety of fracture studies. Unfortunately, quantitative studies are hampered because crack lengths cannot be observed during propagation and the phenomenon of crack arrest is influenced by specimen geometry.

Stable crack propagation also has been obtained by Suresh (ref. 5) and co-workers by means of far field cyclic compression loading of double cantilever beam (DCB) type fracture specimens. Stable fatigue cracks have been propagated from notch roots in monolithic and whisker reinforced ceramic specimens for distances of 1 to $2 \mathrm{~mm}$. Crack propagation is theorized to occur during unloading as a result of residual tensile stresses generated from the extremely high compressive fields near the crack tip. Stable crack extension occurs within a zone of irreversible damage localized near the crack tip. Far field cyclic compression provides a useful method of developing sharp throughthickness cracks, however, propagated crack lengths lie within a region of material which has been damaged extensively. Fracture evaluations may suffer from the unknown effects of the compressive damage zone.

Nose and Fujii (ref, 6) have developed a sharp crack initiation technique, termed the Bridge Indentation (BI) method, for ceramic materials. The BI method compressively loads standard MOR bar specimens in a direction transverse to the longitudinal axis. A stress riser, for transverse Poisson's stresses, is produced by either a fine saw cut or a microhardness indentation. A stable crack is propagated from the stress riser and arrested in the beam. Precracked beams are then loaded more conventionally through three- or four-point bending for evaluation of the fracture toughness, a technique termed the single-edgeprecracked-beam method (SEPB). Results indicate that the SEPB method can be used to accurately measure fracture toughness values, however, the method does not allow quantitative study of stable crack growth.

\section{SPECIMEN AND LOADING SYSTEM DEVELOPMENT}

The development of a stable crack growth test procedure in brittle materials resulted from an evolutionary series of several specimen designs and loading configurations. The design goal was an extremely stiff displacement controlled loading system and a specimen geometry which produced a decreasing energy release rate with crack extension. Displacement control was chosen because a load controlled system affects the characteristics of both the energy release rate function and the elastic energy distribution. Considerable effort 
was also placed on reducing the dependency of the test on grip alignment and grip contact stresses, known sources of extraneous crack initiation.

Control of elastic displacements becomes crucial if the brittle fracture specimen is included in the integral or primary load train. Measurement of the total crack mouth opening displacement (CMOD) lead to the observation that many prototype specimens failed within a few microns of crack opening displacement. Due to the unpredictable and sensitive nature of crack growth in ceramic materials, the desired resolution of the displacement controlled system was two to three orders of magnitude lower than the expected total displacement. Conventional closed loop test machines are incapable of this degree of displacement control.

Another design objective was to minimize the transfer of elastic energy into the fracture specimen during crack extension. Special consideration was given to the distribution of elastic energy stored in the load train and its redistribution during crack extension. Unstable crack propagation rates in ceramic materials are extremely high and the reaction time for conventional closed-loop systems much too slow to be effective during crack extension. Active closed-loop interaction of a servo-hydraulic load frame with a specimen is not possible at the inception of unstable crack extension. The elastic response of the load system alone influences the test during fracture.

The final specimen design and loading scheme which satisfies the requirements for stable crack growth in brittle materials is shown in figure $1(\mathrm{a})$. The loading scheme is unique in that the specimen is attached as a secondary component to the load train. The primary component of the load train is a solid cylinder which is axially compressed during loading.

The typical loading configuration for fracture tests is, in principle, similar to that shown in figure $1(\mathrm{~b})$ where the specimen is included as an integral, or primary part, of the load train. In this configuration, the link with the greatest compliance, ideally the test specimen, contains the greatest portion of the strain energy. A redistribution of strain energy occurs as specimen compliance increases with crack extension. The specimen absorbs all of the redistributed energy which is then available for sustaining crack extension. Instability occurs when the elastic energy available to the specimen exceeds that required to propagate a crack.

The "secondary" loading scheme of figure 1(a) shows the specimen coupled in parallel with the primary loading component. The component with the greatest compliance contains the least strain energy in a parallel system. Although an increase in specimen compliance causes an increase in the effective compliance of the parallel components, the resulting change in the distribution of strain energy is minimal compared to that for the primary loading scheme. In addition, a decreasingly small amount of the energy that is redistributed is apportioned to the fracture specimen. Most of the energy is absorbed by axial compression of the loading pin. The benefits of a secondary loading scheme are its isolation of the specimen compliance, its ability to minimize redistribution of energy during crack extension and a high degree of control on the displacements applied to the fracture specimen. 


\section{SPECIMEN GEOMETRY}

Overall dimensions of the design specimens were limited by the size of the bulk ceramic material which was $40 \mathrm{~mm}$ wide $50 \mathrm{~mm}$ long and $10 \mathrm{~mm}$ thick. The specimen was chosen to be loaded through displacements applied to the crack mouth. In theory, fixed crack mouth displacement loading produces a selfarresting stress field in front of the advancing crack. The final geometry chosen is detailed in figure 2 .

High local stresses and strains produced near grip points from mismatched surfaces were found to be problematic to the stability of crack extension. Elastic deformations related to the point contact of loading rollers on the flat surface of the specimen critically affected fracture stability. The stored elastic energy was transferred to the specimen during crack extension creating instability. It was thought that a conformed grip and specimen surface would reduce these damaging elastic deformations.

A circular loading pin and circular hole in the test specimen best satisfied testing needs. Both the pin and the receiver hole can be machined to high degree of accuracy and the circular geometry of the pin is maintained under load. An added benefit of a radially expanding, circular loading pin is the self-alignment of the test specimen and grips with increasing load. Compressive contact loads are distributed over the inside area of the receiver hole, thereby reducing contact stresses and the probability of failure at the load point. The only elastic strain energy stored in the loading system which can be transferred during crack extension results from the radial compressive strains superimposed on the pin by crack mouth opening forces. These radial forces, and subsequent displacements in the pin, are extremely small. Reduced contact displacements and forces results in a minimal amount of stored elastic energy .

\section{SPECIMEN PREPARATION AND LOADING TECHNIQUES}

Specimens are first machined as flat plates with a width of $35 \mathrm{~mm}$ a length of $45 \mathrm{~mm}$ and a thickness of $1.25 \mathrm{~mm}$. The receiver hole is rough cut with a diamond coring bit and then surfaced with a fine diamond coated grinding mandrel. The final diameter of the receiver hole varies by $25 \mu \mathrm{m}$ about a nominal $5.00 \mathrm{~mm}$. A $0.25 \mathrm{~mm}$ wide prenotch is machined to a depth of $15 \mathrm{~mm}$ with a diamond slicing saw. The tip of the prenotch has a tapered cross-section through the specimen thickness extending a distance of $3 \mathrm{~mm}$ to facilitate initiation of a sharp crack.

Proper selection of the initial diameter of the unstressed load pin is important for successful testing. A maximum $22 \mathrm{kN}$ axial load on the pin produces a radial expansion of $8 \mu \mathrm{m}$. Approximately $5 \mu \mathrm{m}$ of CMOD is required to complete a test. The available displacement is more than sufficient to fail the fracture specimen, however, axial compressive stresses of $1.0 \mathrm{GPa}$ may be produced if the entire $8 \mu \mathrm{m}$ displacement range is needed. A set of 25 loading pins, having a size range from $30 \mu \mathrm{m}$ above to $30 \mu \mathrm{m}$ below the nominal $5.00 \mathrm{~mm}$ diameter, is used to obtain the proper initial pin diameter. The difference between pin diameters is $2.5 \mu \mathrm{m}$. The load pin possessing the closest fit with the receiver hole is selected to initiate a test. Since high loads may be necessary to complete a test, careful alignment of the pin center is required to 
minimize bending and the probability of buckling. The unsupported length of the pin was kept at a minimum to reduce the risk of buckling by utilizing a socket assembly shown in Figure 3 .

Crack mouth opening displacements are measured with conventional extensometry. Crack lengths were obtained from the electrical potential drop induced in a thin film of gold sputtered onto the ceramic surface. Crack lengths were also monitored optically.

The test procedure provides for a very high degree of applied displacement control, although the displacement range of the pin is limited to $8 \mu \mathrm{m}$. Assuming axial pin loads can be controlled to less than $20 \mathrm{~N}$ over a $22 \mathrm{kN}$ range, applied displacements can be theoretically controlled within $7 \mathrm{~nm}$ over the full displacement range. Finer control is capable at smaller ranges. Extremely slow applied displacement rates can be achieved by ramping the axial load.

Load rates of $30 \mathrm{~nm} / \mathrm{hr}$ are achievable with standard closed loop servo hydraulic test frames.

\section{DISCUSSION OF RESULTS}

Controlled crack growth was achieved in $\mathrm{Al}_{2} \mathrm{O}_{3}$ specimens to an a/W ratio in excess of 0.9 (approx. $25 \mathrm{~mm}$.) $\mathrm{An} \mathrm{Al}_{2} \mathrm{O}_{3}$ specimen with a stable crack grown to an a/w ratio greater than 0.80 is shown in figure 4. The results of a typical test are shown in figure 5. Tests were also performed satisfactorily in sodalime glass with similar results. Crack propagation occurs at a pseudostatic rate where crack extension occurs by incremental jumps and arrests. Uncontrollable catastrophic failure was not observed during crack growth in either the ceramic or glass material. Fracture properties will be calculated using CMOD and crack length measurements together with the elastic solution for specimen compliance.

The testing procedure is theoretically insensitive to specimen thickness and thicker specimen should be easily accommodated without increased pin loads. Larger applied displacements can be achieved by increasing pin diameters when testing more compliant materials.

\section{CONCLUSIONS}

1. A pure Mode I fracture specimen has been developed which provides stable, constant cross-section, through thickness cracks in ceramic material systems.

2. Cracks can be propagated stably to an a/W ratio in excess of 0.9 (a distance of $25 \mathrm{~mm}$ with the present specimen geometry.) Longer cracks can be achieved by simply scaling up the dimensions of the specimen.

3. Specimen geometry is simple and easy to machine. The testing procedure provides grip self-alignment and reduces grip contact stresses.

4. Fracture tests can be performed on most conventional test frames since relatively small compressive loads are required and a high degree of applied displacement control can be produced. 


\section{REFERENCES}

1. D. Munz, R.T. Bubsey, and J.E. Srawley, "Compliance and Stress Intensity Coefficients for Short Bar Specimens With Chevron Notches," Int. J. Fract., 16 [8] 359 (1982).

2. R.T. Bubsey, 0. Munz, W.S. Pierce, and J.L. Shannon Jr., "Compliance Calibration of the Short Rod Chevron Notch Specimen for Fracture Toughness Testing of Brittle Materials," Int. J. Fract., 18 [2] 125 (1982).

3. J. Nakayama, "Direct Measurement of Fracture Energies of Brittle Heterogeneous Materials," J. Am. Ceram. Soc., 年 [11] 153 (1965).

4. H.G. Tattersol, and G. Tappan, "The Work of Fracture and Its Measurement in Metals, Ceramics and Other Materials," L. Mater. Sci., 1 [3] 296 (1966).

5. S. Suresh, and J.R. Brockenbrough, "Theory and Experiments of Fracture in Cyclic Compression: Single Phase Ceramics and Ceramic Composites," Acta Metall., $\underline{\underline{36}}$ [6] 1455 (1988).

6. T. Nose, and T. Fujii, "Evaluation of Fracture Toughness for Ceramic Materials by a Single-Edge-Precracked-Beam Method," L. Am. Ceram. Soc., $\underline{\underline{71}}$ [5] 328 (1988).
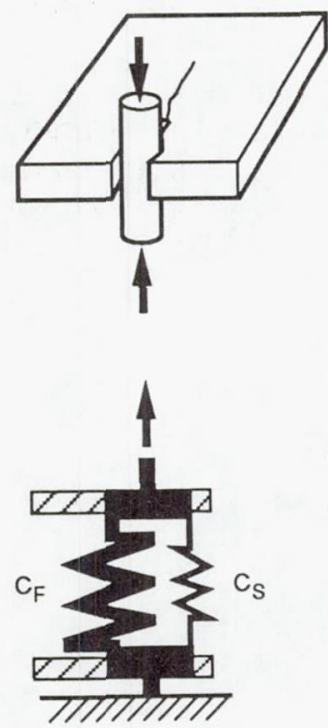

(a) Parallel system.

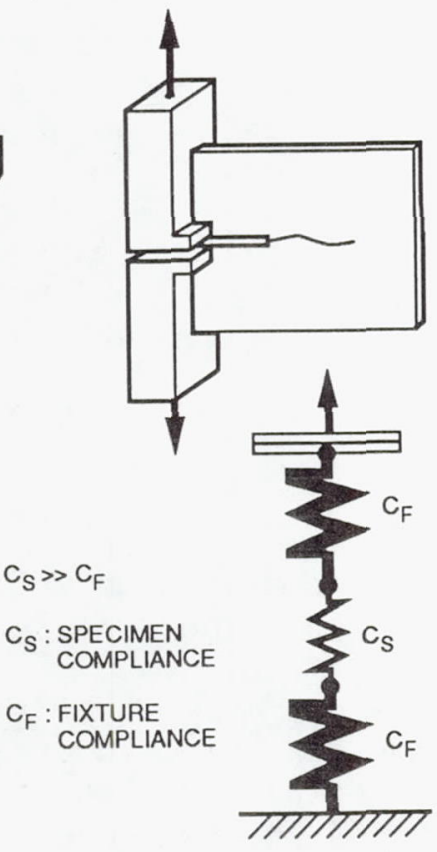

(b) Linear system.

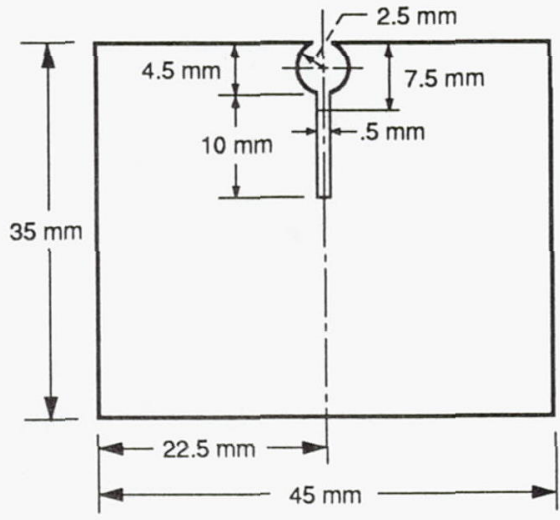

Figure 2. - Specimen geometry.

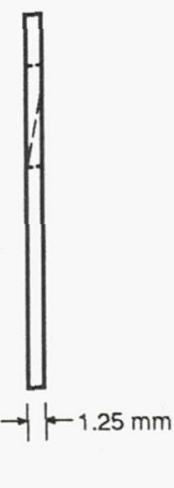

Figure 1. 


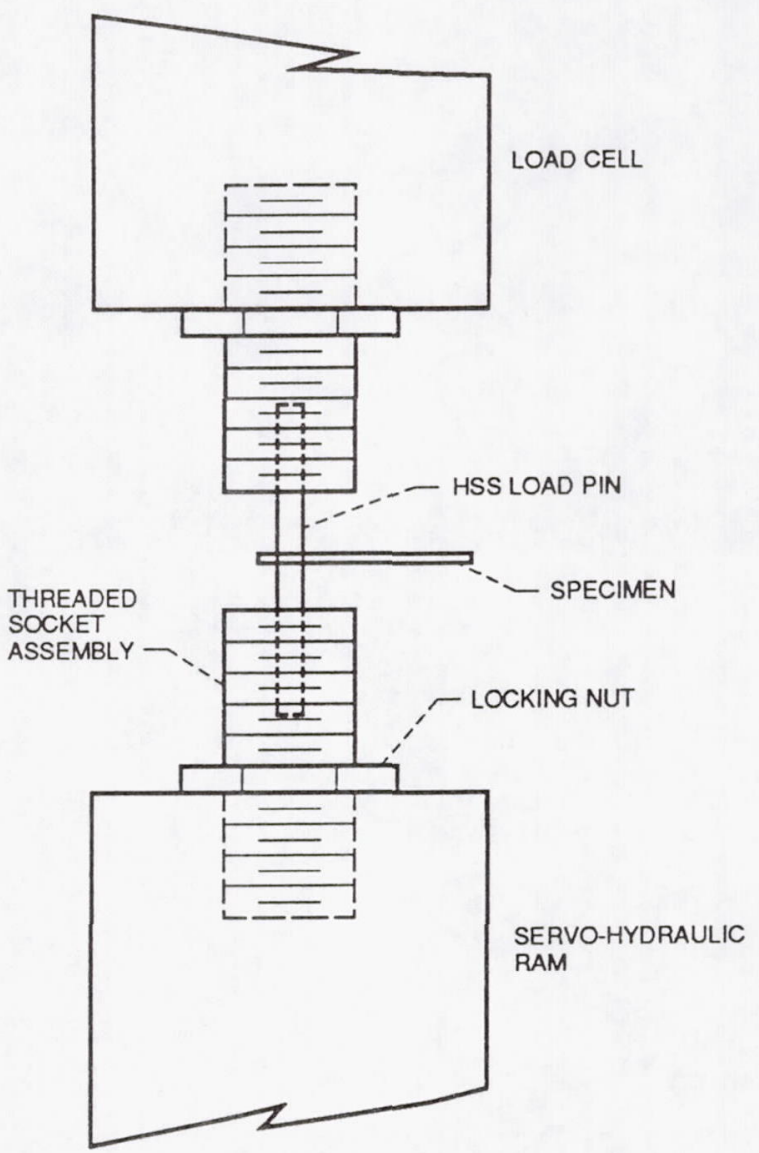

Figure 3. - Socket assembly. 


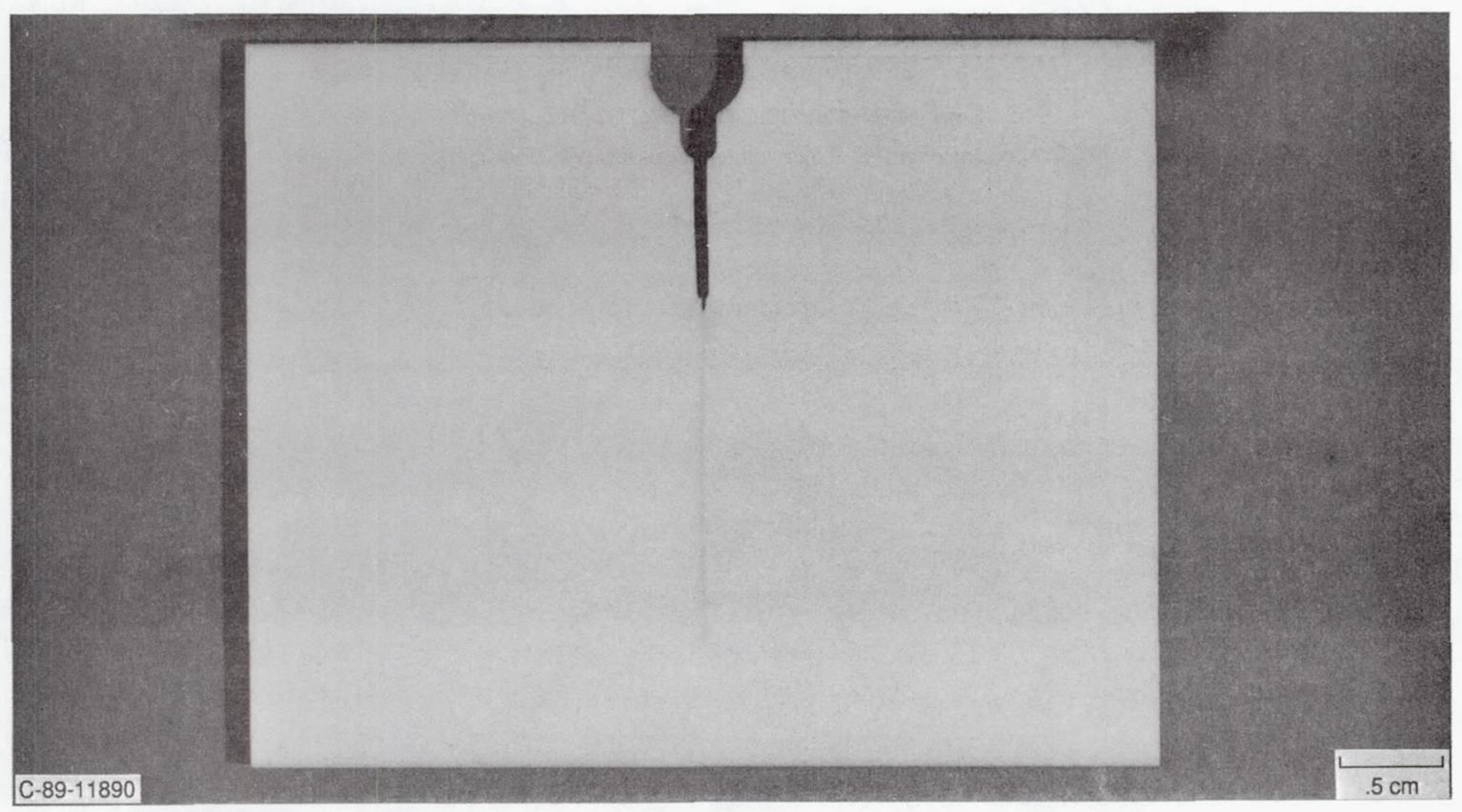

Figure 4. - Stable crack in $\mathrm{Al}_{2} \mathrm{O}_{3}$.

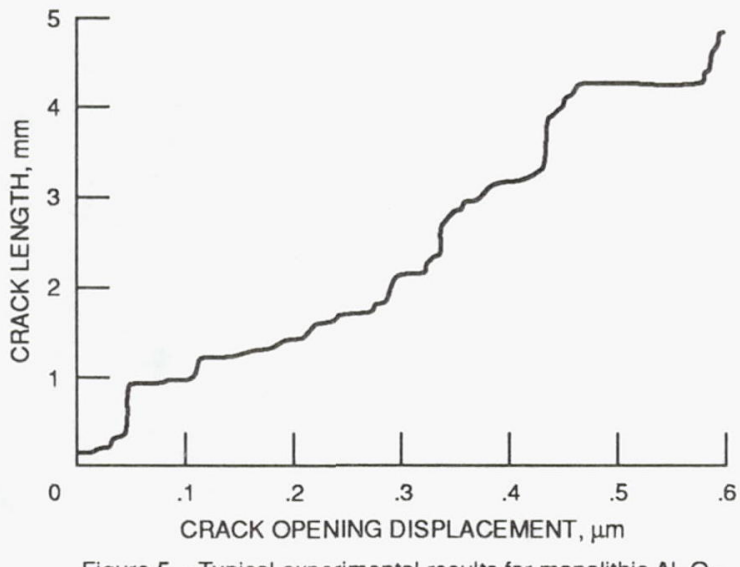

Figure 5. - Typical experimental results for monolithic $\mathrm{Al}_{2} \mathrm{O}_{3}$ ceramic specimen.

8 


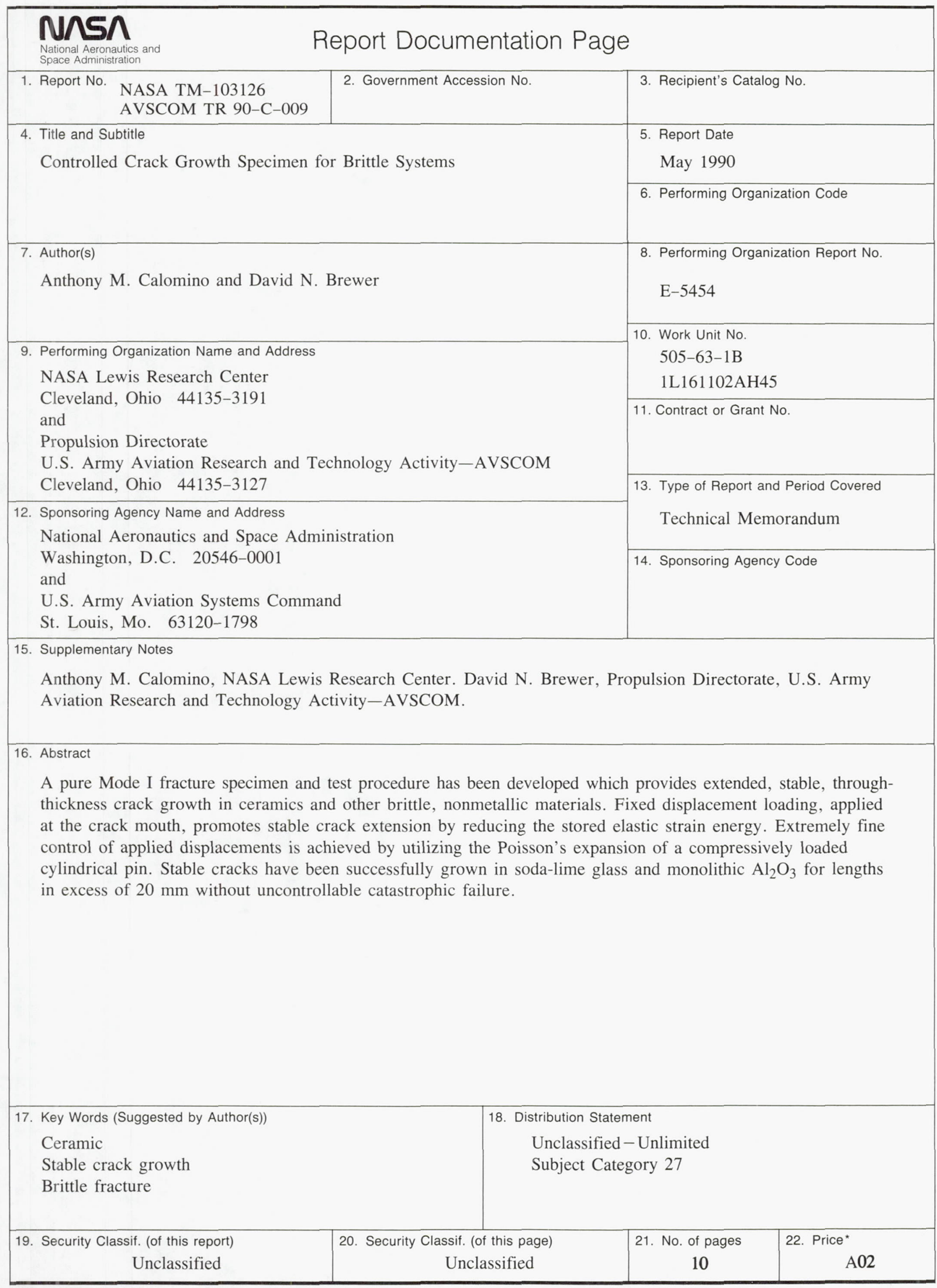

